\title{
METODE ANALYTICAL HIERARCHY PROCESS (AHP) DALAM PEMILIHAN BUDIDAYA IKAN LAUT (STUDI KASUS PADA BALAI PERIKANAN BUDIDAYA LAUT (BPBL) BATAM)
}

\author{
Zainul Munir ${ }^{1)}$ \\ Manajemen Informatika, STMIK GICI, Batam \\ Email : bapakmunir@gmail.com \\ Dedi Rahman Habibie ${ }^{2)}$ \\ Sistem Informasi, STMIK GICI, Batam \\ Email : dedi.habibi@gmail.com
}

\begin{abstract}
Abstrak
Sistem Pendukung Keputusan (SPK) atau dikenal dengan Decision Support System (DSS), pada tahun 1970-an sebagai pengganti istilah Management Information System (MIS). Batam merupakan pulau kaya raya, dimana mempunyai laut yang terdapat ikan melimpah ruah. Penelitian ini bertujuan merancang sistem penunjang keputusan untuk budidaya ikan laut dengan pendekatan metode Analytical Hierarchy Process (AHP), sehingga dapat membantu nelayan dalam memilih ikan yang mudah dibudidayakan. Tahapan penelitian ini yaitu menetapkan alternatif-alternatif dan kriteria dalam sebuah sistem penunjang keputusan untuk budidaya ikan laut. Dalam hal budidaya ikan laut, ada beberapa kriteria dan alternatif agar menjadi ekonomis dan menguntungkan, antara lain kriteria jenis ikan dan alternatif-alternatif yaitu $\mathrm{PH}$ air, Jumlah Pakan, Suhu, dan luas keramba. Tahapan yang dilakukan yaitu menghitung bobot kriteria mencari normalisasi matrik setiap bobot dan kriteria, mengecek konsistensi dengan cara mengitung konsistensi setiap langkah-langkah yang akan dilakukan, maka kriteria atau jenis ikan yang dibudidaya akan mendapatkan nilai bobot tertinggi, selanjutnya akan dilakukan perbandingan setiap kriteria dan alternatif-alternatif, Hasil yang didapatkan adalah nilai bobot dari masing-masing alternatif yang dirangking dari tertinggi sampai terendah. Hasil nilai alternatif budidaya ikan yang telah diberi rangking tersebut dapat digunakan sebagai pendukung keputusan dalam menentukan budidaya pemilihan ikan terbaik di Balai Perikanan Budidaya Laut Batam.
\end{abstract}

Kata Kunci : Sistem Penunjang Keputusan, Budidaya ikan laut, Metode Analytical Process Hierachy (AHP), Badan Perikanan Budidaya Laut (BPLP) Batam.

\section{Abstract}

Decision Support System (DSS) in the 1970s as a substitute for the term Management Information System (MIS). Batam is a rich island, where it has a sea of abundant fish. This study aims to design a decision support system for marine fish farming using the Analytical Hierarchy Process (AHP) approach, so that it can help fishermen in choosing fish that are easily cultivated. The stages of this research are to determine alternatives and criteria in a decision support system for marine fish farming. In the case of marine fish farming, there are several criteria and alternatives to be economical and profitabel, including criteria for fish species and alternatives, namely water PH, number of feed, temperature, and cage area. The steps taken are calculating the criteria weight looking for normalization matrix for each weight and criteria, checking consistency by calculating the consistency of each steps to be 
performed, then the criteria or type of fish being cultivated will get the highest weight value, then a comparison of each criterion and alternative will be carried out alternative, the results obtained are the weight value of each alternative ranked from highest to lowest. The results of the alternative value of fish culture that has been given the ranking can be used as a decision support in determining the best fish selection culture in Balai Perikanan Budidaya Laut (BPBL) Batam

Keyword : Decision Support System, Marine Fish Culture, Analytical Process Hierarchy Method (AHP), Batam Aquaculture Fisheries Agency (BPLP).

\section{LATAR BELAKANG}

Perkembangan sistem informasi di dunia pada umumnya dari tahun ketahun sangat signifikan. Kegunaan sistem informasi dapat dimanfaatkan pada semua bidang dikarenakan kemampuan teknologi informasi yang cepat. Dengan perkembangan komputer yang sangat pesat dapat memberikan keuntungan berupa pengolahan data yang sangat cepat, paperless, dan manfaat lainnya, sehingga menghasilkan informasi yang sangat diperlukan.

Teknologi komputer dengan kekuatan prosesnya telah memungkinkan pengembangan sistem informasi ke berbagai bidang. Dengan memanfaatkan teknologi komputer, didapat manfaat berupa kemudahan menyimpan, mengorganisasi dan melakukan pengambilan terhadap berbagai data. Kemajuan teknologi ini kemudian menawarkan banyak kemudahan pada berbagai aspek kehidupan, mulai dari kebutuhan pribadi sampai kegiatan bisnis. Bahkan pada budidaya ikan dapat memanfaatkan sistem penunjang keputusan dengan metode Analytical Hierarchy Process (AHP). Batam merupakan salah satu daerah bahari di propinsi Kepulauan Riau dengan wilayah seluas 251.810,71 $\mathrm{Km}^{2} \quad$ (25.181.071 Ha). Sedangkan berdasarkan batas luas wilayah terluar kota sejauh 4 mil laut sehingga luas Kota Batam sebesar 390.900 Ha. Sebagai salah satu kota yang mempunyai karakteristik wilayah kepulauan, Kota Batam memiliki beberapa pulau besar (Pulau Batam, Pulau Rempang, Pulau Galang, Pulau Galang Baru, Pulau Bintan, Pulau Natuna dan Pulau Bulan). Kota Batam yang memiliki garis pantai sepanjang $172 \mathrm{Km}$ itu diperkirakan memiliki potensi pengembangan budidaya laut seluas 61.131,8 Ha., yang terdiri dari 10.709,7 Ha. untuk coastal marine culture dan 50.422,0 Ha. untuk offshore marine culture. Kawasan laut yang berpotensi untuk pengembangan coastal marine culture tersebar di 5 kecamatan, yakni Kecamatan Galang, Kecamatan Kuala Kampar, Kecamatan Bulang, Kecamatan Belakang Padang dan Kecamatan Nongsa. Secara geografis, Kota Batam merupakan wilayah yang strategis, karena berbatasan langsung dengan Singapura dan Malaysia, sementara pada sisi yang lainnya berbatasan dengan beberapa daerah lainnya, yaitu Riau, Sumatera Selatan, Jambi dan Kalimantan Barat. Budidaya Ikan Laut merupakan salah satu cara untuk meningkatkan pendapatan nelayan di Pulau Batam, sejak tahun 2013 [1] nelayan di pulau Batam rata-rata sudah beralih dari nelayan tangkap dengan pukat menjadi nelayan pembudidaya ikan laut dengan sistem keramba, Keramba adalah sebutan untuk sebuah tambak ikan berbahan jaring yang dibuat untuk menampung ikan-ikan 
yang dibudidayakan. Kesulitan budidaya ikan laut dapat mengurangi hasil panen dan cenderung tidak menguntungkan.

Dengan adanya sistem penunjang keputusan dengan metode Analytical Hierarchy Process (AHP) untuk budidaya ikan laut diharapkan sangat membantu nelayan keramba untuk memilih ikan yang menguntungkan untuk dibudidayakan. Dengan penentuan Alternatif dan kriteriakriteria dari budidaya ikan laut dengan metode Analytical Hierarchy Process $(A H P)$ dapat menghasilkan informasi bagi nelayan dalam memilih ikan yang dapat menghasilkan panen terbaik. Sistem penunjang keputusan ini menggunakan kriteria jenis ikan dan alternatif-alternatif yaitu PH air, Jumlah Pakan, Suhu, dan luas keramba.

\section{METODE PENELITIAN}

Penelitian ini dilaksanakan pada bulan April - September 2019 dengan obyek penelitian di Balai Perikanan Budidaya Laut Batam yang terletak di Pulau Setokok, Kota Batam.

Metode penelitian ini menggunakan metode survei yaitu dimana metode yang digunakan untuk mendapatkan hasil riset dalam bentuk opini atau pendapat dari orang lain yang berinteraksi langsung dengan objek yang diamati. Tujuan utama dari metode ini adalah untuk mendapatkan gambaran umum melalui sampel.

Kerangka kerja dalam melakukan penelitian dianggap perlu agar hasil penelitian dapat dicapai secara maksimal seperti yang terdapat pada gambar tahapan penelitian dibawah ini :

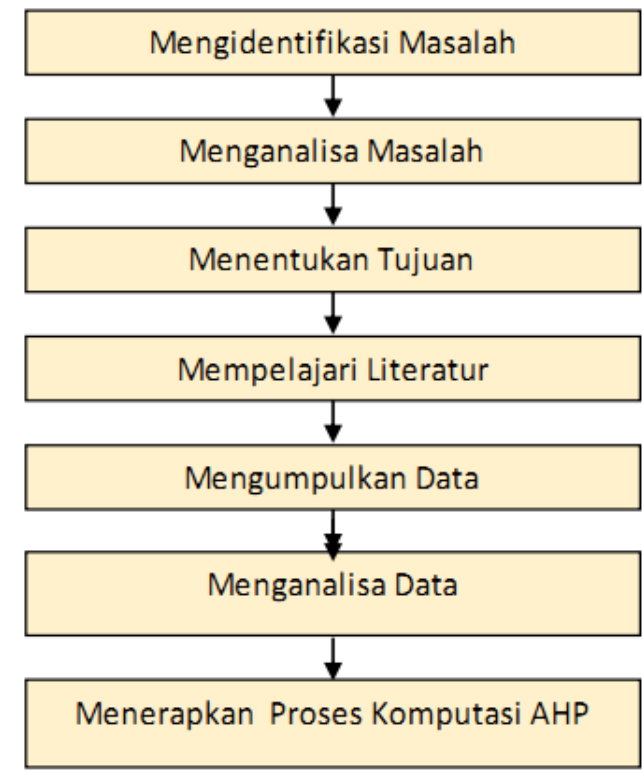

Gambar 1. Kerangka Kerja

Pada dasarnya langkah-langkah Metode AHP adalah [2]:

1. Mendefinisikan masalah dan menentukan solusi yang diinginkan, lalu menyusun hierarki dari permasalahan yang dihadapi. Penyusunan hierarki adalah dengan menetapkan sasaran sistem seara keseluruhan pada level atas.

2. Menentukan prioritas elemen.

a. Langkah pertama adalah membuat perbandingan pasangan, yaitu membandingkan elemen secara berpasangan sesuai dengan kriteria yang diberikan.

b. Matriks perbandingan berpasangan diisi menggunakan bilangan untuk merepresentasikan kepentingan relatif dari suatu elemen terhadap elemen lainnya.

3. Sintesis Hal-hal yang dilakukan dalam langkah ini adalah :

a. Menjumlahkan nilai-nilai dari setiap kolom pada matriks.

b. Membagi setiap nilai dari kolom dengan total kolom yang 
bersangkutan untuk memperoleh normalisasi matriks.

c. Menjumlahkan nilai-nilai dari setiap baris dan membanginya dengan jumlah elemen untuk mendapatkan nilai rata-rata.

4. Mengukur konsistensi dalam pembuatan keputusan, penting untuk mengetahui seberapa baik konsistensi yang ada karena tidak menginginkan keputusan berdasarkan pertimbangan dengan konsistensi yang rendah. Halhal yang dilakukan dalam langkah ini adalah:

a. Mengalikan setiap nilai pada kolom pertama dengan prioritas relatif elemen pertama, nilai pada kolom kedua dengan prioritas relatif elemen kedua, dan seterusnya.

b. Menjumlahkan setiap baris.

c. Hasil dari penjumlahan baris dibagi dengan elemen prioritas relatif yang bersangkutan.

d. Menjumlahkan hasil bagi diatas dengan banyaknya elemen yang ada, hasilnya disebut $\lambda$ maks.

5. Menghitung Consistency Index (CI) dengan rumus :

$$
\mathrm{CI}=(\lambda \text { maks }-\mathrm{n}) / \mathrm{n}
$$

Dimana $\mathrm{n}=$ banyaknya elemen

6. Menghitung Consistency Ratio (CR) dengan rumus :

$\lambda$ maks $=$ Jumlah elemen pada matriks Y N

a. Menghitung nilai Consistency Index (CI)

$\mathrm{CI}=\lambda$ maks $-\mathrm{N}$

$\mathrm{N}-1$

b. Menghitung Consistency Ratio (CR)

$\mathrm{CR}=\mathrm{CI}$

Random Index (tabel)

$\mathrm{CR}=\mathrm{CI} / \mathrm{RC}$

Keterangan : $\lambda$ maks $=$ Maximum Eigen Value

$$
\begin{aligned}
& \mathrm{N}=\text { Ukuran Matriks } \\
& \mathrm{CR}=\text { Consistency Ratio } \\
& \mathrm{CI}=\text { Consistency Index } \\
& \mathrm{IR}=\text { Indeks Random } \\
& \text { Consistency }
\end{aligned}
$$

7. Memeriksa konsistensi hierarki. Jika nilainya lebih dari $10 \%$, maka penilaian dari data judgment harus diperbaiki. Namun jika rasio konsistensi (CI/IR) kurang atau sama dengan 0,1, maka hasil perhitungan bisa dinyatakan benar.

\section{Menganalisa data}

Metode Analytical Hierrchy Process (AHP) [12] dapat memecahkan masalah kompleks, dimana kriteria yang diambil cukup banyak, struktur masalah yang belum jelas, dan ketidakpastian tersedianya data statistik yang akurat. Dalam menyelesaikan permasalahan dengan Analytical Hierrchy Process (AHP) ada beberapa prinsip yang harus dipahami, diantaranya adalah:

1. Membuat Hierarki

Menetapkan suatu tujuan (goal), selanjutnya diuraikan ke dalam kriteria, kemudian menentukan alternatif atau pilihan penyelesaian masalah.

2. Penentuan Prioritas Elemen

Membuat matriks perbandingan berpasangan untuk membandingkan elemen elemen secara berpasangan sesuai dengan kriteria yang diberikan.

Pada Analytic Hierarchy Process terjadi penyusunan permasalahan ke dalam suatu struktur hirarki sehingga pengambil keputusan semaksimal mungkin dapat melibatkan semua faktor yang perlu dipertimbangkan dan akan terlihat jelas 
kaitan antara faktor yang satu dengan yang lain [3].

Adapun struktur hierarki AHP ditampilkan pada gambar berikut:

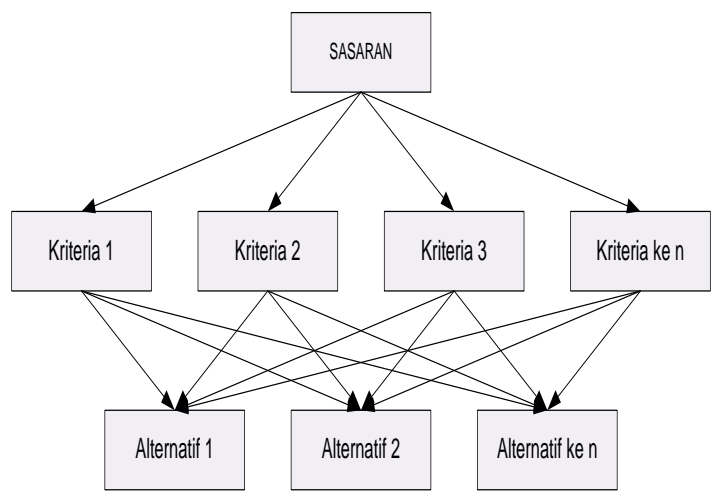

Gambar 2. Struktur Hirarki AHP

Hirarki yang terlihat Gambar 2 adalah bentuk hirarki AHP dalam memilih alternatif dan kriteria, penjelasannnya seperti berikut :

1. Sasaran, yaitu tujuan utama yang hendak dicapai dalam sistem pendukung keputusan ini. Sasaran dalam penelitian ini adalah balai budidaya ikan laut yang dalam hal ini dikhususkan untuk BPBL Batam;

2. Kriteria yang digunakan adalah Lingkungan keramba, Kualitas Air, Luas Keramba, PH Air dan Kedalaman Keramba;
3. Alternatif yang digunakan pada penerima budidaya ikan laut ini yaitu Ikan Bawal, Kakap, Kerapu;

1) Membuat prioritas elemen.

a.Langkah pertama dalam menentukan prioritas elemen adalah membuat perbandingan berpasangan, yaitu memebandingkan elemen secara berpasangan sesuai kriteria yang diberikan.

b. Matrik perbandingan berpasangan diisi menggunakan bilangan untuk mempresentasikan kepentingan relatif dari suatu elemen terhadap elemen yang lain.

2) Menghitung nilai prioritas kriteria dengan rumus menjumlah matriks baris hasil langkah ke 4 dan hasilnya 5 dibagi dengan jumlah kriteria.

3) Menyusun alternatif-alternatif yang telah ditentukan dalam bentuk matriks berpasangan untuk masingmasing kriteria. Sehingga akan ada sebanyak $n$ buah matriks berpasangan antar alternatif.

4) Masing-masing matriks berpasangan antar alternatif sebanyak $\mathrm{n}$ buah matriks, masing masing matriksnya dijumlah per kolomnya.

5) Menghitung nilai prioritas alternatif masing-masing matriks berpasangan antar alternatif dengan rumus.

Tabel 1. Perhitungan Kriteria

\begin{tabular}{|c|l|c|c|c|c|c|c|c|c|l|l|}
\hline No. & \multicolumn{1}{|c|}{ Nama Kriteria } & \multicolumn{7}{|c|}{ Pilih Nilai } & Nama Kriteria \\
\hline 1 & Lingkungan Keramba & 5 & 4 & 3 & 2 & 1 & 2 & 3 & 4 & 5 Kualitas Air \\
\hline 2 & Lingkungan Keramba & 5 & 4 & 3 & 2 & 1 & 2 & 3 & 4 & 5 Luas Keramba \\
\hline 3 & Lingkungan Keramba & 5 & 4 & 3 & 2 & 1 & 2 & 3 & 4 & 5 PH Air \\
\hline 4 & Lingkungan Keramba & 5 & 4 & 3 & 2 & 1 & 2 & 3 & 4 & 5 Kedalaman Keramba \\
\hline 5 & Kualitas Air & 5 & 4 & 3 & 2 & 1 & 2 & 3 & 4 & 5 Luas Keramba \\
\hline 6 & Kualitas Air & 5 & 4 & 3 & 2 & 1 & 2 & 3 & 4 & 5 PH Air \\
\hline
\end{tabular}




\begin{tabular}{|c|l|c|c|c|c|c|c|c|c|l|l|}
\hline 7 & Kualitas Air & 5 & 4 & 3 & 2 & 1 & 2 & 3 & 4 & 5 & Kedalaman Keramba \\
\hline 8 & Luas Keramba & 5 & 4 & 3 & 2 & 1 & 2 & 3 & 4 & 5 & PH Air \\
\hline 9 & Luas Keramba & 5 & 4 & 3 & 2 & 1 & 2 & 3 & 4 & 5 & Kedalaman Keramba \\
\hline 10 & PH Air & 5 & 4 & 3 & 2 & 1 & 2 & 3 & 4 & 5 Kedalaman Keramba \\
\hline
\end{tabular}

Tabel 2. Tabel Eigen

\begin{tabular}{|c|c|c|c|c|c|c|c|c|}
\hline \multirow[t]{2}{*}{ No. } & Alternatif & K01 & K02 & K03 & K04 & K05 & \multirow[t]{2}{*}{ Nilai } & \multirow[t]{2}{*}{ Rank } \\
\hline & $\begin{array}{l}\text { Eigen } \\
\text { Kriteria }\end{array}$ & 0,325 & 0,216 & 0,260 & $\mathbf{0 , 0 7 7}$ & 0,122 & & \\
\hline 1 & $\begin{array}{l}\text { A001 - } \\
\text { Lingkungan } \\
\text { Keramba }\end{array}$ & 0,414 & 0,353 & 0,479 & 0,175 & 0,300 & $\mathbf{0 , 3 8 5}$ & 1 \\
\hline 2 & $\begin{array}{l}\text { A002- } \\
\text { Kualitas Air }\end{array}$ & 0,201 & 0,077 & 0,213 & 0,088 & 0,260 & 0,176 & 2 \\
\hline 3 & $\begin{array}{l}\text { A003 - Luas } \\
\text { Keramba }\end{array}$ & 0,068 & 0,135 & 0,088 & 0,137 & 0,212 & 0,111 & 5 \\
\hline 4 & $\begin{array}{l}\text { A004 - PH } \\
\text { Air }\end{array}$ & 0,102 & 0,229 & 0,141 & 0,215 & 0,139 & 0,153 & 4 \\
\hline 5 & $\begin{array}{l}\text { A005- } \\
\text { Kedalaman } \\
\text { Keramba }\end{array}$ & 0,216 & 0,206 & 0,079 & 0,385 & 0,089 & 0,175 & 3 \\
\hline
\end{tabular}

6) Menguji konsistensi setiap matriks berpasangan antar alternatif dengan rumus masing-masing elemen matriks berpasangan pada langkah 2 dikalikan dengan nilai prioritas kriteria. Hasilnya masing-masing baris dijumlah, kemudian hasilnya dibagi dengan masing- masing nilai prioritas kriteria sebanyak a1, a2, a3,...an.

\begin{tabular}{|c|c|c|c|c|c|c|c|c|}
\hline $\begin{array}{l}\mathbf{N} \\
\mathbf{0}\end{array}$ & $\underset{\mathbf{f}}{\text { Alternati }}$ & $\begin{array}{c}\text { K0 } \\
1\end{array}$ & $\begin{array}{c}\text { K0 } \\
2\end{array}$ & K03 & $\begin{array}{c}\text { Ko } \\
4\end{array}$ & $\begin{array}{c}\text { K0 } \\
5\end{array}$ & $\begin{array}{c}\text { Nil } \\
\text { ai }\end{array}$ & $\begin{array}{l}\text { Ra } \\
\text { nk }\end{array}$ \\
\hline & $\begin{array}{l}\text { Eigen } \\
\text { Kriteria }\end{array}$ & $\begin{array}{l}0,3 \\
30\end{array}$ & $\begin{array}{l}0,1 \\
99\end{array}$ & $\mathbf{0 , 3 3 0}$ & $\begin{array}{l}0,08 \\
5\end{array}$ & $\begin{array}{l}0,0 \\
56\end{array}$ & & \\
\hline 1 & $\begin{array}{l}\text { A001- } \\
\text { Bawal }\end{array}$ & $\begin{array}{l}0,2 \\
57 \\
\end{array}$ & $\begin{array}{l}0,4 \\
02 \\
\end{array}$ & 0,333 & $\begin{array}{l}0,14 \\
5 \\
\end{array}$ & $\begin{array}{l}0,2 \\
22 \\
\end{array}$ & $\begin{array}{r}0.2 \\
718 \\
\end{array}$ & 1 \\
\hline 2 & $\begin{array}{l}\text { A002-- } \\
\text { Kakap }\end{array}$ & $\begin{array}{l}0,0 \\
88 \\
\end{array}$ & $\begin{array}{l}0,1 \\
37 \\
\end{array}$ & 0,167 & $\begin{array}{l}0,06 \\
2\end{array}$ & $\begin{array}{l}0,2 \\
22\end{array}$ & $\begin{array}{r}0.1 \\
352 \\
\end{array}$ & 5 \\
\hline 3 & $\begin{array}{l}\text { A003 - } \\
\text { Kerapu }\end{array}$ & $\begin{array}{l}0,1 \\
54\end{array}$ & $\begin{array}{l}0,2 \\
44\end{array}$ & 0,167 & $\begin{array}{l}0,26 \\
5\end{array}$ & $\begin{array}{l}0,1 \\
11\end{array}$ & $\begin{array}{r}0.1 \\
882\end{array}$ & 3 \\
\hline
\end{tabular}

7) Menghitung Lamda max dengan rumus $\alpha \max =\Sigma \alpha / \mathrm{n}$

8) Menghitung $\mathrm{CI}$ dengan rumus $\mathrm{CI}=\alpha$ $\max /(n-1)[4]$

\section{HASIL DAN PEMBAHASAN}

Implementasi aplikasi sistem pendukung keputusan budidaya ikan laut dengan metode AHP terdapat menu yaitu form menu di antaranya menu utama, login, halaman admin, kriteria, alternatif, seleksi AHP dan hasil seleksi 
Pada halaman menu utama akan menampilkan informasi tentang metode AHP terdapat halaman menu login administrator.

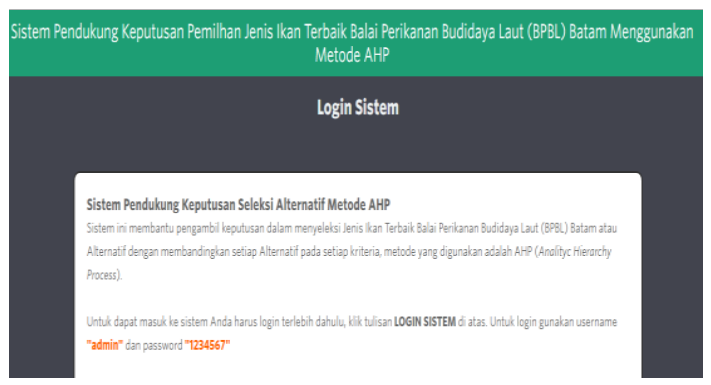

Gambar 3. Halaman Muka

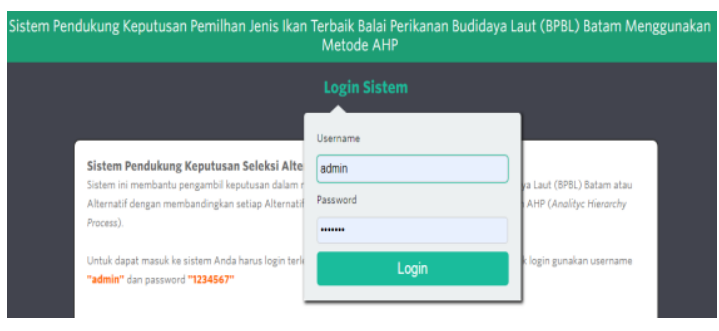

Gambar 4. Halaman login

Pada halaman admin akan menampilkan beberapa menu diantaranya menu home, seleksi baru, data kriteria, data alternatif, seleksi AHP dimana hasil kondisi budidaya ikan laut yang akan berfungsi sesuai dengan kebutuhan admin dalam menentukan ikan.
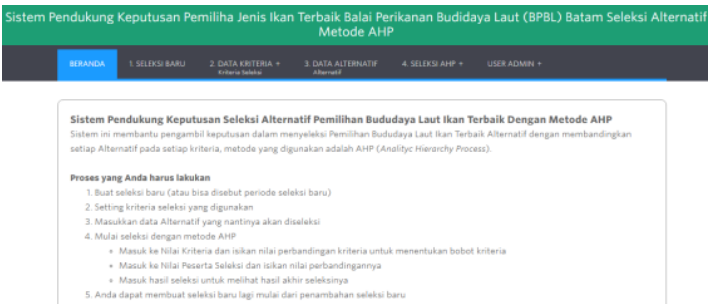

\section{Gambar 5. Halaman keterangan pemakaian sistem}

Menentukan nilai Kriteria

Pada halaman kriteria akan menampilkan input kriteria dan keterangan kriteria dimana tiap kriteria dapat dihapus dan diedit, dimana admin harus mengisi semua halaman web untuk menyimpan data kriteria dalam memilih ikan yang dibudidayakan

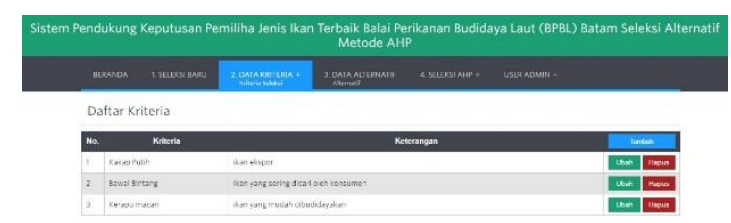

\section{Gambar 6. Halaman input dan edit nilai} kriteria

Menentukan Nilai Alternatif

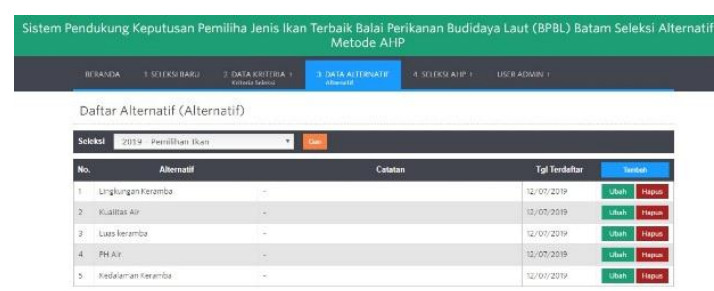

Gambar 7. Halaman input dan edit nilai

Perbandingan Kriteria

\section{alternatif}

Dimana membandingkan bobot kriteria setiap kriteria diberi nilai sesuai dengan data yang didapat dari petugas di BPBL Batam. 


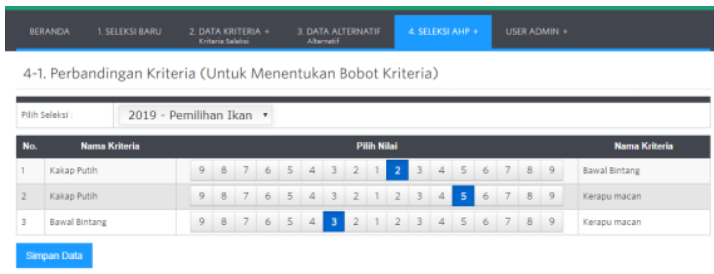

Gambar 8. Halaman menentukan bobot kriteria

Setelah dihasilkan matrik nilai perbandingan serta nilai normalisasi dan nilai eigen dan cek konsistensi

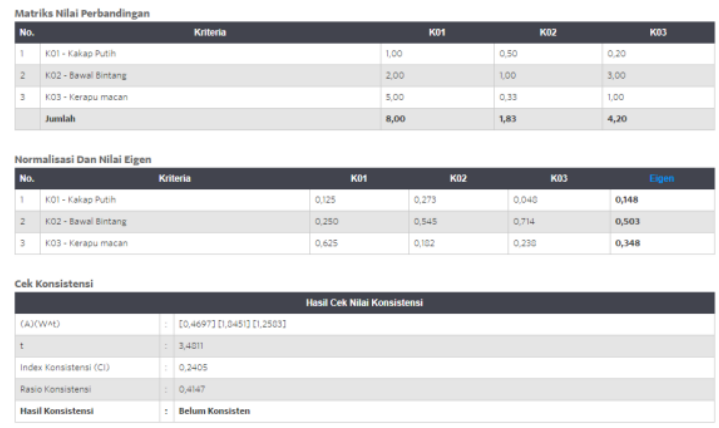

Gambar 9. Halaman Olahan matrik dan normalisasi, nilai Eigen dan cek konsistensi

Pada halaman seleksi AHP terdapat tabel perbandingan dimana admin dapat membuat pebandingan seleksi antara Alternatif yang ada maka dihalaman seleksi AHP terdapat tabel normalisasi dan cek konsisten atau tidak, data yang akan diperoleh.

Perbandingan Nilai Alternatif dan Nilai Kriteria

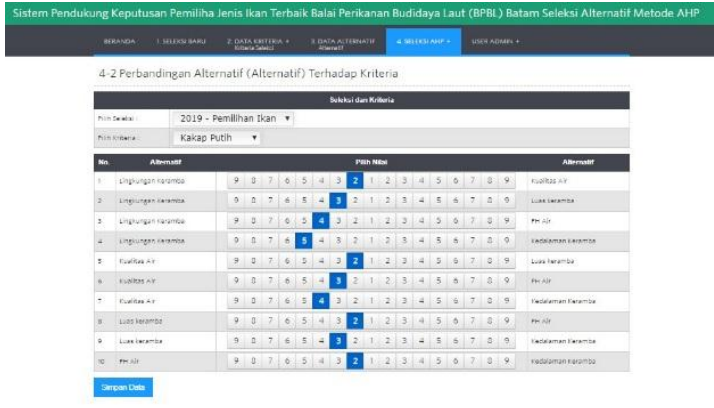

\section{Gambar 10. Halaman perbandingan alternatif dan kriteria}

Grafik Nilai Eigen dan Hasil

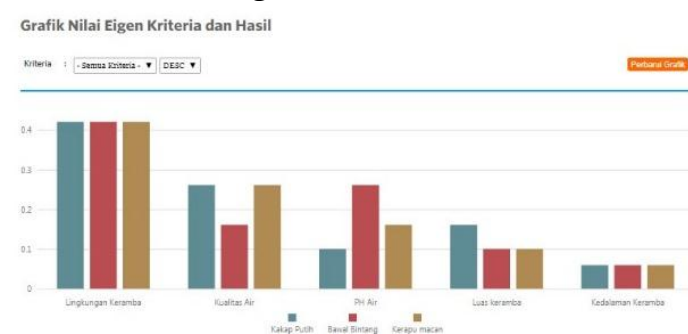

Gambar 11.Halaman tampilan grafik nilai eigen

Pada halaman hasil akan menampilkan seluruh hasil dan grafik ikan yang layak dengan kondisi lingkungan budidaya ikan laut.

\section{SIMPULAN}

Metode AHP untuk budidaya ikan laut pada Balai Perikanan Budidaya Laut Batam dirancang dan dibangun untuk menetapkan ikan yang dapat dibudidayakan pada kriteria yang ada. Penerapan implementasi menghasil sistem pengambilan keputusan yang sesuai dengan perhitungan dari Metode AHP dimana penyeleksian ikan yang akan dibudidayakan sesuai dengan kondisi keramba. Dengan adanya metode AHP yang telah dibuat dapat mempercepat penyeleksian Ikan yang akan 
dibudidayakan sesuai dengan kondisi keramba.

Nilai kriteria yang telah diolah dari data lapangan didapat data keramba yang berisikan ikan kakap, keramba ikan bawal, ikan kerapu. Data Olahan diinput ke perhitungan metode AHP dengan menggunakan matrik dan normalisasi dihasilkan nilai Eigen dan grafik hasil.

\section{UCAPAN TERIMA KASIH}

Terima Kasih yang sebesar-besarnya atas dukungan oleh Kemenristek Dikti terhadap penelitiaan ini melalui Hibah Penelitian Dosen Pemula Tahun Anggaran 2019 beserta Pimpinan LLDIKTI Wilayah $X$. Terima Kasih yang sebesar-besarnya Kepada Pimpinan Balai Perikanan Budidaya Laut (BPBL) Batam Kementerian Kelautan dan perikanan Republik Indonesia, serta Petugas lapangan, Terimakasih juga kepada LPPM Sekolah Tinggi Manajemen Informatika dan Komputer (STMIK) GICI beserta Kaprodi STMIK GICI yang selalu memberikan dukungan dan pembinaan dalam melakukan penelitian ini.

\section{DAFTAR PUSTAKA}

[1]Bardansyah (2014), "Sistem Pendukung Keputusan Penentuan Sekolah Favorit Tingkatan Sekolah Menengah PertamaSwasta Dengan Menggunakan Metode Analitycal Hierarchy Process (AHP) " Pelita Informatika Budi Darma, Vol. VI, No. 3, Hal. 21-25

[2]Ganda Terta(2014) , "Sistem Pendukung Keputusan Untuk Menentukan Penerima Bantuan Sosial Tahunan Dari Perusahaan Dengan Metode Analytical Hierarchy Process (Studi Kasus : Grand Palladium Medan)". Pelita Informatika Budi Darma, Vol. VIII, No. 3, Hal. 100106
[3]Muhammad, Anwar, Syarifuddin, Amrullah (2016), "Aplikasi Pendukung keputusan Pemilihan Bakal Calon Anggota legislatif oleh Partai Politik di Indonesia dengan Metode AHP” Journal Vol.5 No.2, Hal. 4-10

[4]Rima Ayuningtyas, Sistem Pendukung Keputusan Dalam Menentukan Jenis Budidaya Ikan Dengan Mengukur Kualitas Air Menggunakan Metode Fuzzy Tsukamoto (Studi Kasus : Balai Benih Ikan di Pengujan Kabupaten Bintan), Jurusan Teknik Informatika, Universitas Maritim Raja Ali Haji. 